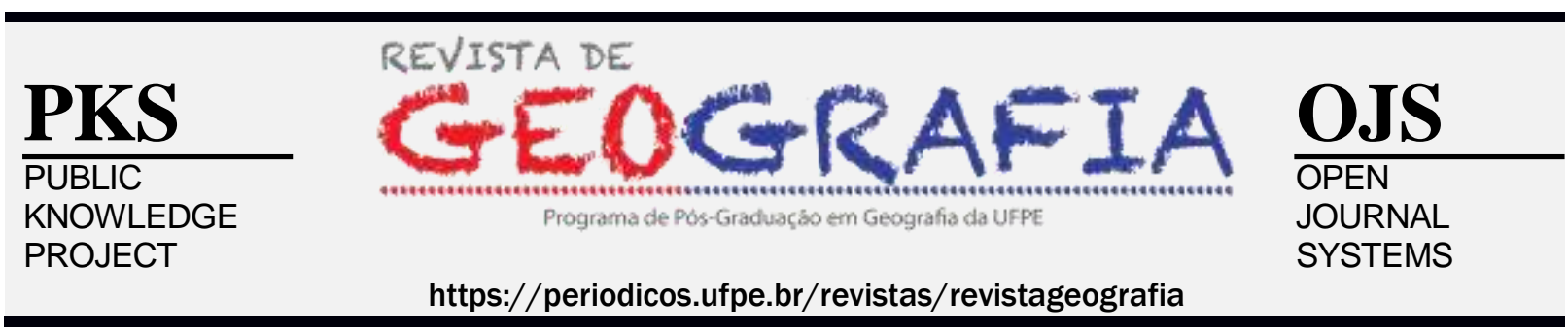

\title{
O ENSINO DE GEOGRAFIA NO CONTEXTO DO SEMIÁRIDO NORDESTINO
}

\author{
Maria Juliana do Nascimento ${ }^{1}$, Cícero Nilton Moreira da Silva ${ }^{2}$ \\ ${ }^{1}$ Programa de Pós-Graduação em Ensino (PPGE), da Universidade do Estado do Rio Grande do Norte \\ (UERN), Campus Avançado de Pau dos Ferros (CAPF). E-mail: mjuhnascimento@gmail.com \\ ${ }^{2}$ Professor Permanente do Programa de Pós-Graduação em Ensino (PPGE), da Universidade do Estado do \\ Rio Grande do Norte (UERN), Campus Avançado de Pau dos Ferros (CAPF). E-mail: \\ ciceronilton@yahoo.com.br
}

Artigo recebido em 19/02/2020 e aceito em 24/07/2020

\begin{abstract}
RESUMO: Este trabalho discute acerca da educação contextualizada na perspectiva da convivência com o semiárido e como isso acontece no ensino de Geografia. Quanto aos procedimentos metodológicos, utilizamos revisão bibliográfica com base em: Andrade (1973; 2006), Straforini (2004), Freire (2005), dentre outros que discutem temas voltados à convivência com o semiárido, à educação contextualizada e ao ensino de Geografia. Iniciamos nosso trabalho apresentando uma descrição do semiárido, na qual abordamos o processo de colonização, bem como a gestação dos estigmas presentes nos discursos que envolvem a região. Posteriormente, apresentamos alguns fundamentos da Educação contextualizada. Na sequência, fazemos um relato dos pressupostos da Ciência Geográfica e da disciplina Geografia, bem como das principais correntes de pensamento que as influenciaram, em seguida abordamos como o ensino de Geografia acontece na contemporaneidade; por fim, trazemos uma discussão sobre o ensino de Geografia na perspectiva da educação contextualizada, a fim de entender como a convivência com o semiárido pode ser praticada e percebida no ensino de Geografia. Dessa forma, acreditamos conduzir os professores à uma reflexão sobre o ensino de Geografia na região, de modo que percebam a importância da educação contextualizada na formação crítico-social do aluno.
\end{abstract}

Palavras-chave: Educação contextualizada; Ensino de Geografia; Semiárido.

\section{THE TEACHING OF GEOGRAPHY IN THE NORTHEAST SEMIARID CONTEXT}

\begin{abstract}
This paper discusses the contextualized education in the perspective of living with the semiarid and how it happens in the teaching of Geography. As for methodological procedures, we used bibliographic review based on: Andrade (1973; 2006), Straforini (2004), Freire (2005), among others who discuss themes focused on living with the semiarid, contextualized education and teaching of Geography. We started our work by presenting a description the semiarid region, in which we approach the colonization process, as well as the gestation of the stigmas present in the speeches that involve the region. Subsequently, we present some fundamentals contextualized education. In sequence, we report on the assumptions of Geographic Science and the discipline Geography, as well as the main currents of thought that influenced them, then we approach how the teaching of Geography happens in contemporary times; finally, we bring a discussion about the teaching of Geography from the perspective of contextualized education, in order to understand how living with the semiarid can be practiced and perceived in the teaching of Geography. Thus, we believe to lead teachers to a reflection on the teaching of Geography in the region, so that they realize the importance of education contextualized in the student's social-critical.
\end{abstract}

Keywords: Contextualized education; Geography teaching; Semiarid. 


\section{INTRODUÇÃO}

O semiárido brasileiro enfrenta, desde o período de sua colonização, problemas de ordem ambiental, e também carência de ações públicas, no sentido de possibilitar uma melhor convivência da população sertaneja com o meio em que vive. Desde este tempo, já se falava em medidas de combate à seca, discurso que acaba por disseminar a ideia de que a região é inóspita, rudimentar, atrasada e que sua população é inferior, em comparação com os habitantes de outras regiões brasileiras.

Acreditamos que uma forma pela qual podemos mudar esse imaginário é por meio da educação. Mas não é qualquer educação, e sim uma educação contextualizada, comprometida socialmente com a realidade local, que busque, junto aos sujeitos desse processo, desvendar os discursos construídos acerca da região e das pessoas que ali vivem. Para tanto, é necessário que haja a construção do currículo escolar que concentre temas relativos à realidade sertaneja, visando desmistificar estereótipos e contribuir para a convivência com o semiárido.

Nesse sentido, nosso trabalho tem como objetivo apresentar o ensino de Geografia sob a ótica da educação contextualizada no semiárido. Trata-se de um trabalho de cunho qualitativo, que se utilizou de uma revisão bibliográfica com base nos autores: Andrade (1973; 2006), Straforini (2004), Freire (2005), dentre outros que discutem em seus trabalhos os principais temas abordados no presente artigo.

Para tanto, iniciamos nosso trabalho apresentando uma descrição acerca do semiárido, na qual abordamos o processo de colonização, bem como a gestação dos estigmas presentes nos discursos que envolvem a região. Posteriormente, apresentamos alguns fundamentos acerca da Educação contextualizada. Em um terceiro momento, fazemos um relato dos pressupostos da Ciência Geográfica e da disciplina Geografia, bem como das principais correntes de pensamento que as influenciaram, em seguida abordamos como o ensino de Geografia acontece na contemporaneidade e, finalmente, apresentamos alguns delineamentos de como a convivência com o semiárido acontece dentro do ensino de Geografia.

\section{UM OLHAR GEOGRÁFICO SOBRE O SEMIÁRIDO}

Geograficamente, o Instituto Brasileiro de Geografia e Estatística (IBGE) divide o Brasil em cinco (05) grandes regiões político-administrativas: Norte, Nordeste, Centro- 
Oeste, Sudeste e Sul. A região Nordeste é a maior, em termos de número de estados constituintes, formada por nove (09) unidades federativas, sendo elas: Alagoas, Bahia, Sergipe, Pernambuco, Rio Grande do Norte, Ceará, Paraíba, Piauí e Maranhão. Dentro do Nordeste existe ainda outra divisão “[...] em quatro grandes regiões que são, a um só tempo, naturais e geográficas, dando às mesmas os nomes consagrados pela tradição: Zona da Mata, Agreste, Sertão e Meio Norte" (ANDRADE, 1973, p. 25).

Nessa divisão, o Sertão é a maior das sub-regiões, “[...] ocupando, aproximadamente, 49\% da região nordestina" (ANDRADE,1973, p. 40). No Nordeste, assim como no Brasil como um todo, os primeiros habitantes foram os indígenas, que viviam em relação harmônica com a natureza, utilizando os recursos de forma sustentável apenas para sua sobrevivência.

Segundo Santos (2010), com a expansão dos processos de colonização no Brasil, e a entrada dos colonizadores para o Sertão, a cultura indígena passa a sofrer ataques. E, a partir da fixação dessa população colonizadora branca no Sertão, a seca ganha visibilidade e passa a ser reconhecida como um problema no século XVIII.

De acordo com Silva (2006), os principais estereótipos acerca do Sertão e dos sertanejos começam a surgir nessa época, pois ao enxergarem a seca como fator prejudicial às produções agrícolas e à população, os colonizadores passaram a fazer pedidos de ajuda ao Reino de Portugal que, por sua vez, entendia que tais problemas eram consequências da preguiça dos sertanejos.

Desde esse período, a seca está ligada politicamente às questões seculares da classe hegemônica de poder regional, que faz este fenômeno natural ser concebido como fator prejudicial à condição econômica do semiárido nordestino. Por outro lado, ao solicitar medidas do Estado no auxílio a tal problemática, os "coronéis" viram que o "problema da seca" poderia ser algo rentável. A esse respeito, Bursztyn (2008, p. 100101) enfatiza que:

\footnotetext{
Como a ação do Estado se intensificava a cada seca, esta passou a ser desejável pelos políticos locais, já que, desta forma, poderiam obter os meios materiais para comprar sua importância política (distribuição dos fundos públicos condicionada a sua legitimação pela via eleitoral), além, é claro, de tirar proveito, individualmente, enquanto produtores beneficiados.
}

Pelo exposto, fica claro que as medidas empreendidas eram de caráter assistencialista e paliativas, com o intuito de ajudar na sobrevivência da população local. 
Somente no século XX é que são criados órgãos para atuar de maneira permanente na questão do semiárido, no entanto esses órgãos agiam sob o discurso de combate à seca. Atualmente, o paradigma da seca, que é um fenômeno natural e que não pode ser combatido, ganha outros contornos analítico-interpretativos - o que se deve existir, na verdade, são medidas que venham mitigar os seus efeitos sob a população: o paradigma da convivência com o semiárido (Malvezzi, 2007).

Este discurso é produzido pela elite e tem como palavra-chave a seca. Nas palavras de Castro (1996, p.306) ela representa, para além da falta de chuva, "miséria, analfabetismo, doença, descapitalização, natureza hostil etc.”. Mas é também vista como "falta d'água e como necessidade de recursos para obtê-la" (CASTRO, 1996, p. 306). E é nesse sentido que o discurso se intensifica, para que a elite obtenha os recursos por parte do Estado.

Sobre esse discurso, Castro (1996) destaca, ainda, que com o passar dos tempos o mesmo assume um caráter duplo. De um lado "atribui à natureza dificuldades que explicam os problemas sócio - econômicos da Região". Por outro lado, o discurso mais recente "vê na escassez pluviométrica, que dificulta a reprodução de pragas, e na fertilidade de grandes extensões de solos um enorme potencial para a agricultura irrigada de caráter empresarial" (CASTRO, 1996, p. 297-298).

De acordo com esses aspectos, surgidos ainda no Brasil colonial, a imagem do semiárido foi veiculada nacionalmente como uma região de sofrimento e flagelo. Tais estigmas são reproduzidos ainda hoje, isso porque, como afirma Reis (2010, p. 112), “[...] a imprensa nacional e os que escreveram sobre esta região, tendo como parâmetros apenas uma época do ano, ou apenas um ângulo da região, não perceberam a sua complexidade".

Como colocado por Albuquerque Jr. (2011), este fato resulta do desconhecimento que as populações das outras regiões do país tinham do Norte (hoje Nordeste), construíam uma imagem acerca da região através do que viam e ouviam pela imprensa, que, por sua vez, reproduzia o que era repassado pelos representantes regionais, sobretudo no parlamento, como um apelo ao governo federal, a fim de angariar recursos sob o discurso de combate à seca. No entanto, esses recursos acabavam por beneficiar primordialmente a eles mesmos, como enfatiza Bursztyn (2008), sobre o saldo das feitorias do Departamento Nacional de Obras Contra as Secas (DNOCS), que foi basicamente a construção de açudes nas terras de médios e grandes proprietários. É com base nesse processo histórico de formação e ocupação do semiárido, e nas imagens 
construídas em torno deste, que o Nordeste e o próprio nordestino têm suas imagens estigmatizadas.

\title{
FUNDAMENTOS BASILARES DA EDUCAÇÃO CONTEXTUALIZADA
}

Para esta seção do trabalho, trazemos uma discussão acerca dos fundamentos que estabelecem a educação contextualizada e abordamos, ainda que brevemente, a forma como esta deveria acontecer para que possa promover a emancipação do sujeito.

A lei $\mathrm{n}^{\circ}$ 9.394, de 20 de dezembro de 1996, que estabelece as diretrizes e bases da educação nacional (LDB), com base na Constituição Federal (CF) de 1988, preconiza em seu Artigo 28 que:

\footnotetext{
Art. 28. Na oferta de educação básica para a população rural, os sistemas de ensino promoverão as adaptações necessárias à sua adequação às peculiaridades da vida rural e de cada região, especialmente:

I - conteúdos curriculares e metodologias apropriadas às reais necessidades e interesses dos alunos da zona rural;

II - organização escolar própria, incluindo adequação do calendário escolar às fases do ciclo agrícola e às condições climáticas;

III - adequação à natureza do trabalho na zona rural (BRASIL, 1996).
}

Ou seja, defende, assim como Cavalcanti (2005, p. 71), que a tarefa da educação

\begin{abstract}
é a de tornar os conteúdos veiculados objetos de conhecimentos para o aluno, o que requer constante diálogo do sujeito do conhecimento, portador de uma cultura determinada, com esses outros objetos culturais, no sentido de atribuirlhes significados próprios, o que é necessário para um processo de aprendizagem significativa.
\end{abstract}

Por aprendizagem significativa, essa autora entende que diz respeito ao "resultado da construção própria de conhecimento. É a apropriação de um conteúdo de ensino pelo sujeito, o que implica uma elaboração pessoal do objeto de conhecimento" (CAVALCANTI, 2005, p. 71).

Nesse sentido, relacionar o que se aprende na escola com o que se vivencia cotidianamente é uma forma de relacionar, também, teoria e prática, pois permite que os educandos possam atribuir significado àquilo que é ensinado dentro da escola. Dessa forma, como propõe Freire (2005), através de uma educação problematizadora, os educandos podem se inserir criticamente na realidade que vivenciam. 
Com esse intuito, é importante que os professores façam uso de metodologias que considerem o contexto em que a escola está inserida, sobretudo porque grande parte dos materiais didáticos utilizados nas escolas são produzidos nas regiões Sul e Sudeste, ou seja, encontra-se fora do contexto local dos educandos. Dessa forma, as metodologias da educação contextualizada se caracterizam por serem instrumentos de conciliação entre os processos educacionais propostos pelos programas curriculares e as vivências dos alunos em seu meio social. Morin (2000, p. 36) corrobora com o nosso pensamento ao dizer que "[...] o conhecimento das informações ou dos dados isolados em seu contexto é insuficiente. É preciso situar as informações e os dados no seu contexto para adquirirem sentido".

Desse modo, a educação contextualizada se assemelha ao que Libâneo (2003) propunha defendendo a Pedagogia Crítico-social dos Conteúdos, ao afirmar que é de responsabilidade da escola a difusão de conteúdos “[...] concretos e, portanto, indissociáveis das realidades sociais[...]" (LIBÂNEO, 2003, p. 38-39).

Ainda que não se possa falar de uma educação contextualizada efetivada, há indícios que demonstram que estamos caminhando para tal, isso porque desde a última década do século $\mathrm{XX}$, muitas ações têm se destacado no que pese a influência positiva para o desenvolvimento da educação no Semiárido. Ainda hoje, no século XXI, o Semiárido é marcado por uma forte exclusão social, que vem paulatinamente sendo combatida por meio de um crescente posicionamento crítico da sociedade civil frente ao modo em que a região é tratada nacionalmente. Nesse ínterim, é crescente as proposições no sentido de uma educação que considere o contexto dos alunos, pautada no paradigma de convivência com a seca.

As ações pontuais de intervenção no Semiárido em períodos de estiagem, passam a ser duramente criticadas a partir da década de 1990, em que a sociedade passa a reivindicar ações que corroborem com a perspectiva da convivência com o Semiárido. Nesse contexto, a organização política da sociedade civil vai desencadear na criação da Articulação no Semiárido Brasileiro (ASA) e da Rede de Educação do Semiárido Brasileiro (RESAB).

Essas redes atuam na desconstrução de estereótipos negativos acerca da região e da população local. Dessa forma, a educação contextualizada voltada para a convivência com o Semiárido brasileiro busca a valorização da região por meio da construção de uma visão positiva por parte dos educandos sertanejos acerca da região em que vivem. A 
RESAB propõe uma educação voltada para a convivência com o semiárido, tendo como prioridade a dimensão sociocultural, de forma que haja um diálogo entre os conteúdos historicamente construídos e as vivências dos alunos.

A concepção dos processos educativos propostos pela RESAB mensura-se a partir da produção de conhecimento contextualizado, ou seja, aquele "que a partir do contexto possa articular os diversos saberes/conhecimentos produzidos pela humanidade, objetivando a melhoria das condições de vida no Semiárido Brasileiro" (RESAB 2004, p. $15)$.

Assim, a RESAB atua com base em quatro referências teórico-práticas: currículo contextualizado, gestão compartilhada, formação continuada e, produção de materiais didáticos e paradidáticos. De acordo com Martins e Reis (2004, p. 8)

\begin{abstract}
Para a Rede de Educação do Semiárido Brasileiro - RESAB [...] uma orientação para que consigamos construir propostas e projetos pedagógicos mais reais e que tenham o próprio Semiárido como a principal trama das narrativas e ponto de partida para a comunicação com outros saberes e conhecimentos produzidos pela humanidade que não podem ser negados às nossas crianças, aos nossos jovens e adultos, onde o SAB possa assumir a cena principal para a compreensão do mundo das coisas e das relações em que estamos inseridos.
\end{abstract}

A educação contextualizada preconiza uma adequação dos conteúdos escolares ao espaço em que os alunos vivem, de forma a considerar a cultura e as especificidades da realidade do Semiárido. Para tanto, se faz necessário também uma formação continuada dos professores para que possam compreender as modificações no mundo e a realidade que vivem para além das imagens reproduzidas historicamente pelos grupos hegemônicos. Para Kraus (2015, p.28-29),

\begin{abstract}
O processo de educação contextualizada, a partir da formação continuada dos professores e professoras, almeja ressignificar a prática docente dando autonomia no modo de contextualizar os saberes e as práticas escolares. $\mathrm{O}$ educador se desvincula do livro didático e para assim de ser um mero reprodutor de conteúdos, levando os conteúdos do currículo para a realidade local e vice-versa. Instaura-se, assim, uma relação dialógica dialética que possibilita, a partir de temas geradores, abordar a realidade social, ambiental, histórica, econômica e cultural do Semiárido. O currículo se anima e possibilita a interdisciplinaridades, articulando-se com o mundo vivido.
\end{abstract}

A partir da educação contextualizada ao semiárido, acreditamos que seja possível a construção de uma visão positiva da região junto aos nossos alunos, por meio 
da apresentação das especificidades e potencialidades da mesma, que, por vezes, são encobertas nos discursos hegemônicos.

Uma vez que estamos buscando trabalhar a educação contextualizada na perspectiva do semiárido, podemos ver a filosofia, deste tipo de educação, sendo aplicada em processos educativos que primem por abordar formas de convivência com a região, tais como: preservação dos recursos hídricos, conservação dos solos, manejo da caatinga com criatório de caprinos e ovinos etc. Dessa forma, o professor poderia esclarecer que o semiárido e suas características específicas são resultados de um processo histórico, com influências políticas, sociais, econômicas e culturais e não um ambiente problemático a ser combatido, como se coloca nos discursos de combate à seca, por exemplo.

A educação contextualizada com foco nas questões ambientais, numa leitura contemporânea, e segundo o paradigma da convivência com os longos períodos de estiagem, pode se configurar como uma forma de desenvolvimento para o semiárido nas esferas cultural, social e ambiental. Para além disso, pode contribuir para a construção da identidade do jovem sertanejo, que passará a conhecer melhor a região em que vive, não internalizando os discursos discriminatórios e estereotipados, disseminados nacionalmente.

\title{
O ENSINO DE GEOGRAFIA NA CONTEMPORANEIDADE
}

Nesta seção, apresentamos um breve relato sobre a constituição da Geografia enquanto ciência e os desafios do seu ensino na contemporaneidade. Isto posto, destacamos inicialmente que, desde o seu surgimento, ela passou por diversas mudanças, necessitando estar sempre se adequando para atender às transformações que ocorriam no mundo. Para Nascimento (2004, p. 25),

\begin{abstract}
A história da Geografia está implicitamente associada à história da humanidade, às suas relações com a natureza, à sua evolução. $\mathrm{O}$ "instinto geográfico", ou seja, o sentido de orientação, de localização e de mobilidade no espaço terrestre não integra somente a natureza humana, já que os animais também o possuem em graus diversos. No homem, todavia, esse sentido é trabalhado na razão, para atender, sejam as necessidades elementares de sobrevivência, sejam as necessidades secundárias ou artificiais, cada vez mais complexas e numerosas, decorrentes das características culturais dos grupos ou das sociedades.
\end{abstract}

No período do Renascimento, ampliou-se ainda mais a busca pela compreensão do mundo através da razão. Kant e Foster marcaram esse período, assim como marcam 
as bases da ciência moderna. De modo particular, Kant destacou-se inclusive na compreensão epistemológica da Ciência Geográfica.

No entanto, foi apenas no século XVII que a Geografia, assim como outras áreas do conhecimento, passa a ser diretamente reconhecida com relativa autonomia. Foi a partir de então que houve uma maior sistematização dos conhecimentos, o que ocasionou avanços significativos na constituição das bases teórico-metodológicas da Ciência Geográfica. Todavia, como enfatiza Andrade (2006), foi na Alemanha do século XIX, a partir dos estudos de Alexandre Von Humboldt e Karl Ritter, que a Geografia Moderna teve sua constituição. Posteriormente, também na Alemanha, as formulações de Friedrich Ratzel provocaram, nas palavras de Moraes (2007, p. 67), “[...] um revigoramento do processo de sistematização da Geografia [...]". A influência dos franceses emerge logo em seguida, tendo Paul Vidal de La Blache como principal nome.

Ademais, as contribuições de Ratzel e de La Blache marcam um novo momento da Geografia. Constitui-se, então, a corrente tradicional da Geografia ou a Geografia Clássica, que foi duramente criticada, em meados do século XX, por sua base epistêmica ser fundamentada nas filosofias da natureza, isto é, por ter como base o método positivista e as pesquisas seguirem os moldes dos métodos das ciências naturais, como assinala Gomes (1996).

Dentro desse contexto, ainda no século XIX, a Geografia escolar é institucionalizada, porém só teve um aprofundamento de fato no século posterior. Na verdade, a Geografia escolar surge como parte do processo de institucionalização da Ciência Geográfica e acontece inicialmente em países desenvolvidos.

Ademais, o ensino de Geografia se caracterizava por ter bases positivistas, com uma perspectiva tradicional, na qual o professor era tido como detentor de todo conhecimento e estava no centro do processo educativo. A institucionalização da Geografia brasileira, como salienta Andrade (2006), só acontece após a década de 1930.

Dentro da perspectiva do Neopositivismo ou Positivismo lógico, temos a chamada corrente teorético - quantitativa na década de 1950, responsável por instituir modificações profundas na Geografia. Foi neste período que a Geografia passou a ser considerada Ciência Social. Segundo Corrêa (2000), é dentro desta corrente do pensamento geográfico que o espaço aparece pela primeira vez como conceito-chave da Geografia. Assim sendo, entendemos que, nesta corrente geográfica, "o espaço é 
considerado sob duas formas [...] De um lado através da noção de planície isotrópica e, de outro, de sua representação matricial " (CORRÊA, 2000, p. 20).

Em virtude das mudanças que aconteciam no mundo do século XX, a Geografia tradicional passa a ser criticada. Nesse contexto, destaca-se um grupo de geógrafos que ficam conhecidos como "radicais" ou "marxistas", lançam as bases do que viria a ser a Geografia Crítica em oposição à Geografia tradicional ou Clássica, nos anos 1970. Essa concepção crítica da Geografia está calcada no materialismo histórico e dialético marxista. A mesma tem influência também na Geografia escolar, pois defende a construção da autonomia do aluno, bem como uma aprendizagem significativa que tenha por base as experiências vivenciadas por eles em seu meio social, assim como os conhecimentos que já possuem para que melhor possam compreender e transformar o espaço.

Assim, ficam perceptíveis os primeiros delineamentos do que seria o ensino de Geografia no século XXI, cabendo ao professor analisar as atuais necessidades do ser humano frente aos avanços científicos, tecnológicos, políticos e econômicos, responsáveis pela rápida transformação do mundo no espaço-tempo. Em outras palavras, o ensino de Geografia na contemporaneidade requer muito mais que a mera transmissão de conhecimentos.

Cabe ao professor, portanto, estimular o aluno, por meio de estratégias, a participar ativamente nas aulas, de modo que se sinta sujeito ativo na construção do conhecimento. Para tanto, é compreensível dizer que o ensino de Geografia necessita de profissionais preparados e que estejam atentos às rápidas transformações que veem ocorrendo no contexto atual, em todas as escalas.

Conforme dito anteriormente, a Geografia enquanto Ciência e disciplina escolar passou por intensas transformações, o atual contexto histórico-social é totalmente díspar daquele em que a mesma surgiu. Diante disso, é preciso pensar a Geografia como uma disciplina capaz de auxiliar os alunos na compreensão do mundo e das transformações que ocorrem no mesmo.

Com base nesses aspectos, a Educação Geográfica tem papel importante na conscientização dos alunos sobre as relações e as diversidades que existem no espaço ocupado socialmente. Segundo Straforini (2004, p. 22), “[...] o ensino de Geografia é fundamental para que as novas gerações possam acompanhar e compreender as 
transformações do mundo, dando à disciplina geográfica um status que antes não possuía".

O ensino de Geografia, considerando a assertiva acima, é importante para a formação do cidadão, como bem enfatiza Cavalcanti (2002, p. 11):

\begin{abstract}
O pensar geográfico contribui para a contextualização do próprio aluno como cidadão do mundo, ao contextualizar espacialmente os fenômenos ao conhecer o mundo em que vive desde a escala local à regional, nacional e mundial. $\mathrm{O}$ conhecimento geográfico é, pois, indispensável à formação de indivíduos participantes da vida social, à medida que propicia o entendimento do espaço geográfico e do papel desse espaço nas práticas sociais.
\end{abstract}

Assim, o ensino de Geografia deve proporcionar ao aluno oportunidades para compreensão das transformações que acontecem no espaço geográfico. Esta perspectiva é importante para a formação de um sujeito capaz de reconhecer a sua participação na construção do mesmo, a partir dos conceitos geográficos e de suas próprias vivências.

No entanto, infelizmente, ainda é comum a existência de um ensino de Geografia influenciado pelas práticas tradicionalistas, sob a abordagem mnemônica, ou seja, que preza pela memorização e descrição do espaço, tornando o ensino para o aluno sem significado e, portanto, desinteressante.

É grande e complexo o desafio de construir um ensino de Geografia que proporcione ao aluno compreender, refletir e se posicionar criticamente sobre a realidade por ele vivenciada. Os aspectos teórico-metodológicos e práticos, por sua vez, constituem uma das dificuldades existentes para esse fim. Esta pode ser um reflexo das políticas educacionais que permeiam o ensino de Geografia e que ainda não foram capazes de elaborar uma estrutura curricular que permita a conciliação entre teoria e prática.

$\mathrm{Na}$ contemporaneidade, o ensino de Geografia enfrenta ainda o desafio de construir uma reflexão em um mundo globalizado, cujo espaço geográfico precisa ser entendido numa perspectiva complexa, haja vista as constantes transformações ao qual é submetido. Cavalcanti (2002) corrobora com este pensamento ao dizer que:

No mundo contemporâneo há uma complexificação do espaço que se tornou global. O espaço vivenciado hoje é fluido, é formado por redes com limites indefinidos e/ou dinâmicos extrapola o lugar de convívio imediato. É, também, um espaço extremamente segregado, onde cresce a cada dia o número de excluídos, de violentados, de desempregados, de sem terras, de sem tetos. (CAVALCANTI, 2002, p. 33). 
Essa fluidez do espaço requer do professor um olhar atento para as mudanças, de modo que possibilite desenvolver, junto aos alunos, criticidade em torno das variáveis decorrentes dessas alterações. Isso se faz necessário, no contexto do semiárido, para compreensão da origem dos discursos acerca da região e da população, assim como da questão da seca em sua totalidade.

\section{A CONVIVÊNCIA COM O SEMIÁRIDO NORDESTINO NO ENSINO DE GEOGRAFIA}

Por muito tempo, a educação formal acontecia de acordo com o que Freire (2005) denominava de "educação bancária": o professor transmitia os conhecimentos que possuía e os alunos tinham unicamente que assimilá-los. Se pensarmos o ensino de Geografia de forma particular, vemos que tal perspectiva perdurou (ou perdura) por mais tempo, haja vista que o seu ensino é tido por muitos, ainda hoje, como descritivo e de caráter decorativo, no qual o aluno precisa apenas memorizar as descrições do espaço para conseguir realizar as avaliações. Felizmente, esta visão vem sendo alterada e já podemos testemunhar a construção de uma Geografia humanizada, comprometida com uma compreensão mais ampla dos fenômenos socioespaciais.

Diante disso, refletindo acerca da necessidade de se repensar o ensino no semiárido, entendemos que as discussões suscitadas pela Geografia são capazes de subsidiar um ensino contextualizado, que permita ao aluno construir um sentimento de pertencimento à sua região, como também contribuir para desmistificar certos discursos hegemônicos, que não correspondem à realidade do semiárido e de sua gente.

Dentro dessa perspectiva, destacamos a Educação Contextualizada que surge como meio de fortalecer a pluralidade cultural, a diversidade social e as diferentes realidades, de forma que possibilite um processo de ensino e aprendizagem mais adequado à cada realidade.

Para Menezes e Araújo (2007, p. 42), a educação contextualizada “[...] busca entender que as pessoas se constroem e constroem seu conhecimento a partir de seu contexto, com relações mais amplas". Neste âmbito, contextualizar seria então ampliar o conhecimento a partir de uma abordagem local, relacionando-a com os conteúdos propostos pelo currículo. 
Ratificamos que as Diretrizes Curriculares Nacionais para o Ensino Médio já trazem a discussão sobre educação contextualizada em seu texto elaborado em 1998:

\begin{abstract}
Interdisciplinaridade e contextualização formam o eixo organizador da doutrina curricular expressa na Lei de Diretrizes e Bases da Educação Nacional (1996). Elas abrigam uma visão do conhecimento e das formas de tratá-los para ensinar e para aprender que permite dar significado integrador a duas outras dimensões do currículo de forma a evitar transformá-las em novas dualidades ou reforçar as já existentes: base nacional comum/parte diversificada, e formação geral/ preparação básica para o trabalho (BRASIL, 1998, p. 50).
\end{abstract}

É nesse sentido que deve atuar a educação contextualizada. Logo, trazendo esta concepção de educação para o semiárido, temos como objetivo compreender a história desse lugar, que tem sido contada de forma a encobrir as potencialidades da região, dando ênfase apenas aos "problemas" enfrentados.

Dentro do ensino de Geografia, podemos trabalhar a educação contextualizada em diferentes perspectivas, mas acreditamos que abordá-la, a partir de questões ambientais, pode ser deveras significativo, pois, além de apresentarmos os recursos naturais de que a região dispõe, conseguiríamos abordar aspectos relevantes para a preservação dos mesmos.

A educação contextualizada apresenta um papel sociopolítico relevante, no que se refere à desmistificação dos estigmas construídos historicamente acerca do semiárido e do sertanejo. Tais estigmas são construídos e cristalizados a partir de discursos pejorativos que visam algum benefício próprio, como é o caso do discurso que alimenta a "Indústria da Seca". No entanto, tais questões por não serem abordadas em sala de aula, fazem com que os discursos hegemônicos sejam internalizados pelos alunos da própria região, em razão de não haver uma problematização em sala de aula. Concernente à essa premissa, Bueno e Silva (2008, p. 74) salientam que:

O currículo das escolas localizadas no Semiárido Brasileiro se apresenta desvinculado da vida dos sujeitos ignorando os saberes aí produzidos no cotidiano de homens e mulheres na produção da sua existência, a cultura, o modo ou modos de viver e conviver com as condições climáticas, os enfrentamentos desse fenômeno com o qual aprendem a conviver criando e/ou redescobrindo formas alternativas de produção da vida (...). Encerradas no seu Projeto Pedagógico (que muitos (as) nem sabem do que se trata) e em muito alienígena ao Semiárido Brasileiro, as escolas deixam de realizar a sua função social pertinente aos povos do Semiárido, negando às crianças o direito de compreender o universo do qual fazem parte e, dessa forma, poderem ser capazes de estar no mundo e com o mundo, como ensina Paulo Freire, 
construindo possibilidades de cidadania. Os livros didáticos adotados contribuem de maneira significativa nesse processo de alheamento. Geralmente produzidos na região Sudeste do Brasil veiculam imagens e narrativas que, além de centradas em outra realidade, muitas vezes reforçam o estereótipo de semiárido e de Nordeste de miséria, de impossibilidades, ignorando as especificidades quase sempre transformadas em necessidades, e as inúmeras possibilidades que o Semiárido comporta.

Essa proposta de uma educação contextualizada para a convivência com o semiárido surge na década de 1990, a partir da organização da sociedade civil, e adota o paradigma de convivência com o semiárido, que se opõe ao paradigma de combate à seca tão difundido por décadas. Sendo assim, a sociedade vê na educação contextualizada uma possibilidade de difundir este novo paradigma entre os jovens.

A contextualização, deve despertar nos alunos o sentimento de valorização da cultura, da sabedoria do povo sertanejo, bem como construir uma visão crítica da região. Sobre isso, Martins (2006, p. 61) defende que:

\begin{abstract}
A “educação para a convivência com o semiárido" passa pela escolarização de temas locais tomados em suas amplitudes, implicando não em tratar estes temas como temas prontos, nem de recorrer ao "saber popular" e parar por aí mesmo. Trata-se de agregar novos saberes a estes temas. Como se estivéssemos agregando valor a um produto, o valor a ser agregado aos temas locais é o novo saber.
\end{abstract}

O mesmo autor cita, ainda, a possibilidade de se trabalhar com temas do Nordeste e aborda o exemplo do vaqueiro e as diversas possibilidades de explorar esta temática em sala de aula. Dessa forma, entendemos que, para contextualizar, poderíamos partir daquilo que Freire (2005) denomina de "temas geradores", cuja investigação se daria por meio de "[...] uma metodologia conscientizadora, além de nos possibilitar sua apreensão, insere ou começa a inserir os homens numa força crítica de pensarem seu mundo" (FREIRE, 2005, p. 112).

Trazendo o pensamento de Freire para discorrer acerca da educação contextualizada no semiárido, percebe-se que, a partir de temas locais, o aluno pode começar a pensar criticamente o lugar em que está inserido, assim como compreender temas mais globais. É possível trabalhar as palavras que caracterizem a região, abordando seus diversos aspectos, como no caso do vaqueiro, por exemplo, podendo compreendê-lo a partir da sua importância na formação das cidades interioranas, por intermédio dos "caminhos do gado" e o povoamento dos sertões que, como destaca Costa Neto (2017), 
repercutiu na formação territorial do Nordeste, bem como influenciou a economia da região, refletindo em alguns casos até na nomenclatura de determinadas localidades.

Considerando toda essa discussão, vimos que não se trata de adequar o currículo, mas de construir um que compreenda a realidade em que a escola está inserida e que apresente ao aluno a região em que ele vive, em suas diferentes faces, não permitindo que a "imagem" construída de sua região seja aquela edificada por quem não vive a realidade.

Neste ínterim, quando pensamos a educação contextualizada, a compreendemos como um espaço para a formação do sujeito em seu caráter cultural e político. É por este e outros motivos que trabalhar com educação contextualizada requer qualificação, habilidade, comprometimento e disponibilidade de ambos os sujeitos envolvidos no processo (professor e aluno).

\section{CONSIDERAÇÕES FINAIS}

A Contextualização da Educação deve ser uma perspectiva facilitadora no entendimento dos conteúdos e dos conceitos, a fim de conferir significado ao que é estudado pelos alunos. Esse processo em busca de conhecimento significativo deve propiciar o encantamento acerca do novo, bem como o desencantamento no que pese à desconstrução de certas imagens e discursos cristalizados na cabeça dos educandos. Logo, deve funcionar de modo que o aluno busque, investigue, questione as "verdades" ditas universais, com o propósito de entender como de fato as coisas acontecem.

Na proposta da educação voltada para a convivência com o semiárido, o aspecto político se faz presente de forma muito enfática, no sentido de desmistificar algumas inverdades propagadas historicamente a respeito da região e de sua gente. Dessa forma, percebemos que a educação contextualizada pode funcionar tanto no sentido de descobrir com os alunos aspectos que são omitidos pelos discursos oficiais, quanto na desmistificação de alguns discursos equivocados.

Esperamos que a escola, por meio de uma educação contextualizada, possa formar sujeitos capazes de compreender reflexivamente a realidade em que se encontram, podendo intervir na mesma, com consciência crítica e sabedoria.

\section{REFERÊNCIAS}

ALBUQUERQUE JR., D. M. de. A invenção do Nordeste e outras artes. 5 ed. São Paulo: Cortez, 2011. 
ANDRADE, M. C. de. A terra e o homem no Nordeste. 3 ed. São Paulo: Brasiliense, 1973.

ANDRADE, M. C. de. Geografia: ciência da sociedade. Recife: Universitária/UFPE, 2006.

BRASIL. Ministério da Educação. Conselho Nacional de Educação. Diretrizes curriculares nacionais para o ensino médio. Brasília: MEC/CNE, 1998.

BRASIL. Senado Federal. Lei de Diretrizes e Bases da Educação Nacional: nº 9394/96. Brasília: 1996.

BUENO, R. J.; SILVA, A. P. Educação para a Convivência com o Semiárido Brasileiro. In: JESINE, E.; BATISTA, M. do S. X.; MOREIRA, O. de L. (Orgs). Educação popular e movimentos sociais. João Pessoa: Universitária/UFPB, 2008.

BURSZTYN, M. O poder dos donos: planejamento e clientelismo no Nordeste. 3 ed. Rio de Janeiro: Garamond; Fortaleza: BNB, 2008.

CASTRO, I. E. de. Seca versus seca. novos interesses, novos territórios, novos discursos no NE. In: CASTRO, I. E. de (Org.). Brasil: questões atuais da reorganização do território. Rio de Janeiro: Bertrand Brasil, 1996.

CAVALCANTI, L. S. Ensino de Geografia e diversidade: construção de conhecimentos geográficos escolares e atribuição de significados pelos diversos sujeitos do processo de ensino. In: CASTELLAR, S. (Org.). Educação geográfica: teorias e práticas docentes. São Paulo: Contexto, 2005, p. 66-78.

CAVALCANTI, L. S. Geografia e prática de ensino. Goiânia: Alternativa, 2002.

CORRÊA, R. L. Espaço, um conceito-chave da Geografia. In: CASTRO, I. E. de; GOMES, P. C. da C; CORREAA, R. L. (Orgs). Geografia: Conceitos e temas. 2 ed. Rio de Janeiro: Bertrand Brasil, 2000, p. 15-47.

COSTA NETO, F. A. da. As passagens de gado na formação de demarcações geográficas no município de Marcelino Vieira/RN. Pau dos Ferros: UERN, 2017. (Trabalho de Conclusão de Curso da Graduação em Geografia). No Prelo.

FREIRE, P. Pedagogia do oprimido. 47 ed. Rio de Janeiro: Paz e Terra, 2005.

GOMES, P. C.C. Geografia e modernidade. Rio de Janeiro: Bertrand Brasil, 1996.

KRAUS, Lalita. A educação contextualizada no semiárido brasileiro: entre desconstrução de estereótipos e construção de uma nova territorialidade. Revista de Geografia (UFPE) v. $32, \mathrm{n}^{\mathrm{o}} 1,2015$. 
LIBÂNEO, J. C. Democratização da escola pública: a pedagogia crítico-social dos conteúdos. 19 ed. São Paulo: Loyola, 2003.

MALVEZZI, R. Semiárido - uma visão holística. Brasília: Confea, 2007.

MARTINS, J. S. Anotações em torno do conceito de educação para a convivência com o Semiárido. In: RESAB. Educação para a convivência com o semiárido brasileiro reflexões teórico-práticas da RESAB. Juazeiro: Secretaria Executiva da RESAB, 2006.

MARTINS, J. da S.; REIS, E. S. Proposta político--pedagógica da RESAB: A convivência com o semi--árido como norteadora do processo educacional no semiárido brasileiro (Rascunho--manifesto em andamento). Secretaria Executiva da RESAB, Juazeiro (BA). Anexo 3. Relatório Final da Consultoria COOPERFAJ/UNICEF -- 2004. MENEZES, A. C.; ARAÚJO, L. Currículo, contextualização e complexidade: espaço de interlocução de diferentes saberes. In: RESAB. Currículo, contextualização e complexidade: elementos para se pensar a escola no semiárido. Juazeiro: Selo Editorial RESAB, 2007, p. 33-47.

MORAES, A. C. R. Geografia: pequena história crítica. 21 ed. São Paulo: Annablume, 2007.

MORIN, E. Os sete saberes necessários à educação do futuro. São Paulo: Cortez, 2000. NASCIMENTO, A. L. do. Em torno do conhecimento geográfico. In: ARAUJO, L. M. de. (Org.) Geografia, espaço, tempo e planejamento. Alagoas: Universitária/UFAL, 2004, p. 25-42.

REIS, E dos S. A contextualização dos conhecimentos e saberes escolares nos processos de reorientação curricular nas escolas do campo. 2009. (Tese do Programa de Pós-Graduação em Educação). Salvador: UFBA, 2009.

REIS, E. dos S. Educação para a Convivência com o Semiárido: Desafios e possibilidades. In: Semiárido Piauiense: Educação e Contexto. Campina Grande: INSA, 2010.

RESAB. REDE DE EDUCAÇÃO DO SEMIARIDO BRASILEIRO. Secretaria Executiva da RESAB. Projeto inclusão, universalização e qualidade da educação no semiárido brasileiro (2004). Juazeiro (BA), 2004

SANTOS, J. M. dos. Tecnologias para o semiárido. In: Semiárido Piauiense: Educação e Contexto. Campina Grande: INSA, 2010. 
SILVA, R. M. da. Entre o combate à seca e a convivência com o semiárido: transições paradigmáticas e sustentabilidade do desenvolvimento. 2006. (Tese do Programa de PósGraduação em Desenvolvimento Sustentável). Brasília: UNB, 2006.

STRAFORINI, R. Ensinar Geografia: o desafio da totalidade-mundo nas séries iniciais. São Paulo: Annablume, 2004. 